\title{
PROJETO URBANO EM SÍTIO HISTÓRICO ALIADO A TÉCNICAS COMPENSATÓRIAS EM DRENAGEM URBANA, MARECHAL HERMES, RJ
}

\author{
Rebeca Braga Gomes Drummond ${ }^{1}$
}

Andrea Queiroz da Silva Fonseca Rego ${ }^{2}$

\begin{abstract}
Aline Pires Veról ${ }^{3}$
\section{RESUMO}

Este artigo é resultado do Trabalho Final do Curso de Graduação em Arquitetura e Urbanismo, concluído em Junho de 2014 pela autora', no qual era proposto o planejamento urbano de uma Área de Proteção do Ambiente Cultural (APAC) no bairro de Marechal Hermes, zona norte da cidade do Rio de Janeiro. Foi, então, proposto o uso de técnicas compensatórias em drenagem urbana aliadas ao projeto urbano. $\mathrm{O}$ trabalho busca complementar a pesquisa realizada por uma equipe da Escola Politécnica/UFRJ, a qual realizou estudos em áreas afetadas com falta de planejamento urbano no Rio de Janeiro, destacando os principais aspectos negativos do bairro em questão relacionados à falta de drenagem urbana, propondo melhorias para os mesmos. Nesse sentido, aqui são propostas melhorias que abrangem a utilização de técnicas compensatórias em drenagem urbana, como: reservatórios de lote, trincheiras de infiltração, jardins drenantes, pavimentos permeáveis e reservatórios de detenção. É imprescindível que a falta de planejamento urbano esteja cada vez mais recorrente nas discussões técnicas e científicas, por ser um problema comum à maioria dos bairros do Brasil.
\end{abstract}

PALAVRAS-CHAVE: técnicas compensatórias, drenagem urbana e desenho urbano.

\section{URBAN DESIGN IN HISTORIC SITE COMBINED WITH COMPENSATORY TECHNIQUES IN URBAN DRAINAGE, MARECHAL HERMES, RJ}

\footnotetext{
${ }^{1}$ Arquiteta e Urbanista, Mestranda em Arquitetura, PROARQ-FAU/UFRJ.gomes.rebeca@ymail.com.

${ }^{2}$ Doutorado em Urbanismo, Vice-Coordenadora do Programa de Pós-Graduação em Arquitetura PROARQ/FAU/UFRJ e orientadora do Trabalho Final de Graduação. andrea.queiroz@ufrj.br.

${ }^{3}$ Doutorado em Engenharia Civil, Pesquisadora do Programa de Pós-Graduação em Arquitetura PROARQ/FAU/UFRJ e co-orientadora do Trabalho Final de Graduação. alineverol@fau.ufrj.br.
} 
Revista Nacional de

Gerenciamento de Cidades

\begin{abstract}
This manuscript is the result of the Architecture and Urbanism Undergraduate Final Project, completed in June 2014 by the author", in which it was proposed the urban planning of a "Cultural Environment Protection Area" (APAC, in Portuguese), in Marechal Hermes district, north of the city of Rio de Janeiro. It was, thus, proposed the use of compensatory techniques in urban drainage combined with the urban design. This work aims to complement the research carried out by a team from the Polytechnic School / UFRJ, which conducted studies in areas affected by the lack of urban planning in Rio de Janeiro, highlighting the main negative aspects of the studied neighborhood related to the lack of urban drainage and proposing solutions for them. In this sense, this work proposed the use of compensatory techniques in urban drainage, such as: on-site detention, infiltration trenches, draining gardens, porous pavements and detention reservoirs. It is imperative that the lack of urban planning is increasingly recurrent in the technical and scientific discussions, as it is a common problem to most of Brazil's neighborhoods.
\end{abstract}

KEYWORDS: compensatory techniques, urban drainage and urban design.

\title{
DISEÑO URBANO EN SÍTIO HISTORICO ALIADO A TÉCNICAS COMPENSATORIAS EN DRENAJE URBANO, MARECHAL HERMES, RJ
}

\section{RESUMEN}

Este artículo es el resultado del Trabajo Final de Graduación en Arquitectura y Urbanismo, completado en junio de 2014 por la autora' en el que se propuso la planificación urbana de un "Área de Proteción del Medio Ambiente Cultural" (APAC, em portugués) en el distrito de Marechal Hermes, al norte de la ciudad de Río de Janeiro. Así, se propone el uso de técnicas compensatorias en drenaje urbano combinadas con el proyecto urbano. El trabajo busca complementar la investigación realizada por un equipo de la Escuela Politécnica / UFRJ, que realizó estudios en las zonas afectadas por la falta de planificación urbana en Río de Janeiro, destacando aspectos negativos del barrio en cuestión relacionados con la falta de drenaje urbano, proponiendo mejoras. En consecuencia, aqui se proponen mejoras, que cubren el uso de técnicas compensatorias en el drenaje urbano, tales como: reservatórios en la parcela urbana, zanjas de infiltración, jardines de drenaje, pavimentos porosos y reservatorios de detención. Es imperativo que la falta de planificación urbana sea cada vez más recurrente en los debates técnicos y científicos, ya que se trata de un problema común a la mayoría de los barrios de Brasil.

PALABRAS-CLAVE: técnicas compensatorias, drenaje urbano y diseño urbano.

Os assentamentos humanos, na sua origem, priorizaram a proximidade dos cursos de água. Entretanto, séculos depois, questões tão básicas ainda são objeto 
$\mathbf{T}$

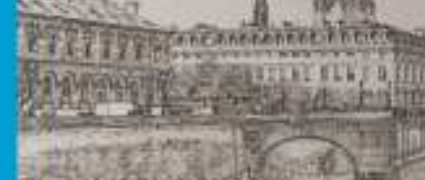

Revista Nacional de

Gerenciamento de Cidades

de discussão, quando a ocupação desordenada de áreas, sem o devido planejamento urbano, que acarretou em grandes áreas impermeáveis, gera problemas de calamidade pública, devido às intensas ocorrências hidrológicas. 0 processo de urbanização altera o ciclo hidrológico, diminuindo a retenção superficial, a infiltração e aumenta os escoamentos superficiais, agravando as cheias.

As ações do poder público para controle das cheias estão voltadas, na maioria das vezes, para soluções com medidas estruturais, como as redes de drenagem, que simplesmente transferem o problema de um lugar para o outro, a jusante na bacia. Essas ações solucionam o problema apenas superficialmente.

Atualmente existem técnicas em drenagem urbana, a maioria delas relacionadas a processos de armazenamento e infiltração das águas pluviais no solo, com a finalidade de reduzir os impactos provocados pela urbanização na hidrografia existente, recuperando os processos hidrológicos durante a urbanização. As técnicas compensatórias, como o próprio nome diz, auxiliam as utilizadas tradicionalmente para projetos de drenagem urbana, garantindo melhores resultados para o controle de problemas resultantes da falta de planejamento urbano e compensando os impactos da urbanização no ciclo hidrológico. Esses conceitos, no Brasil, foram consolidados por BAPTISTA et al. (2005). Alguns autores, como CASTRO et al. (2013); DUARTE (2003); VERÓL \& MIGUEZ (2011); REZENDE et al. (2013); TECEDOR et al. (2013) discutem as principais técnicas compensatórias utilizadas para o controle das cheias.

A drenagem urbana sustentável está relacionada ao conjunto de elementos destinados a recolher as águas pluviais sobre determinada região, conduzindo-as a um destino final apropriado, evitando a transferência das inundações no espaço ou no tempo.

Entende-se que o manejo das águas pluviais urbanas corresponde ao conjunto de atividades, infraestruturas e instalações operacionais de drenagem urbana de águas pluviais, do transporte, detenção ou retenção para o amortecimento de vazões de cheias, do tratamento e disposição final das águas pluviais drenadas associadas às ações de planejamento e de gestão da ocupação do espaço territorial urbano. Lei Federal $n^{\circ}$ 11.445/2007 (BRASIL, 2007). 


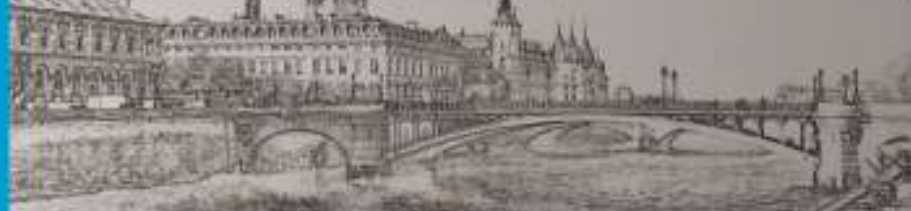

Sistemas de drenagem urbana têm que ser planejados de forma integrada com o crescimento urbano e as soluções de drenagem devem ser integradas com a paisagem urbana. (MIGUEZ et al., 2007).

Este artigo é resultado do Trabalho Final do Curso de Graduação em Arquitetura e Urbanismo, concluído em Junho de 2014 pela autora ${ }^{1}$ no qual era proposto o planejamento urbano de uma Área de Proteção do Ambiente Cultural (APAC) no bairro de Marechal Hermes, zona norte da cidade do Rio de Janeiro, propondo técnicas compensatórias em drenagem urbana aliadas ao projeto urbano.

No projeto, buscou-se a requalificação de áreas livres como calçadas, praças e canteiros, oferecendo áreas com qualidade de permanência, circulação e lazer, com materiais de revestimentos permeáveis, que auxiliam na drenagem, e desenho de áreas livres que ajudam a controlar as cheias da região. $O$ trabalho utilizou informações do projeto "Estudos integrados para avaliação de projeto de intervenção na calha do Rio Acari, RJ, 2007", concluído por uma equipe da Escola Politécnica/UFRJ, que realizou estudos em áreas afetadas pela falta de drenagem urbana na bacia do Rio Acari, no Rio de Janeiro, propondo melhorias. Além disso, também foram realizadas, no contexto do presente trabalho, pesquisas de campo, pesquisas sobre o bairro de Marechal Hermes e busca de referências de projetos com essa abordagem. De posse dessas informações, foram identificadas as áreas que poderiam ser requalificadas, propondo o uso de técnicas compensatórias (reservatórios de lote, trincheiras de infiltração, jardins drenantes, pavimentos permeáveis e reservatórios de detenção) conjugadas ao projeto urbano.

\section{OBJETIVOS}

O objetivo principal deste artigo é reforçar a importância cultural do bairro de Marechal Hermes enquanto patrimônio urbano e edilício, atualmente muito afetada pela insuficiência de gestão urbana, drenagem urbana e estratégias eficazes para 


\section{Revista Nacional de}

Gerenciamento de Cidades

controle das cheias, evidenciando soluções que conciliam a melhoria da qualidade dos espaços livres de uso público com as principais técnicas compensatórias em drenagem urbana, como forma de controle dessas cheias.

De modo mais específico, buscam-se, como objetivos:

- Melhoria nas condições dos espaços livres públicos, qualidade ambiental, saúde e saneamento;

- Economia nos recursos urbanos e na forma de manutenção das técnicas compensatórias em drenagem urbana utilizadas;

- Redução dos alagamentos na região;

- Conservação dos logradouros públicos, calçadas e praças.

\section{ESTUDO DE CASO: O BAIRRO DE MARECHAL HERMES}

\subsection{CONTEXTUALIZAÇÃO URBANA}

Marechal Hermes faz parte da XV R.A. do Rio de Janeiro, subordinada à Subprefeitura da Zona Norte (Figura 1). Fundado em 1ํ de Maio de 1913, é um bairro planejado e se desenvolveu em torno da estação ferroviária. Foi o primeiro bairro operário do Brasil e terceiro planejado do país, tendo sido idealizado para suprir as carências de moradias populares. No centro geométrico do bairro planejado há a Praça XV de Novembro, em torno da qual foram projetadas duas escolas primárias. Ele possui uso estritamente residencial e uma rede de serviços públicos: além das escolas, dispõe de teatro e hospitais. Em uma das ruas principais, Avenida General Osvaldo Cordeiro de Farias está o Hospital Carlos Chagas (1934) um dos primeiros da cidade e o teatro Armando Gonzaga (1954), em frente, projetado por Affonso Eduardo Reidy. Em 30 de Abril de 2013, foi criada a Área de Proteção do Ambiente Cultural (APAC) do Bairro de Marechal Hermes, estabelecendo critérios para sua proteção e determinando o tombamento e a preservação de bens. 


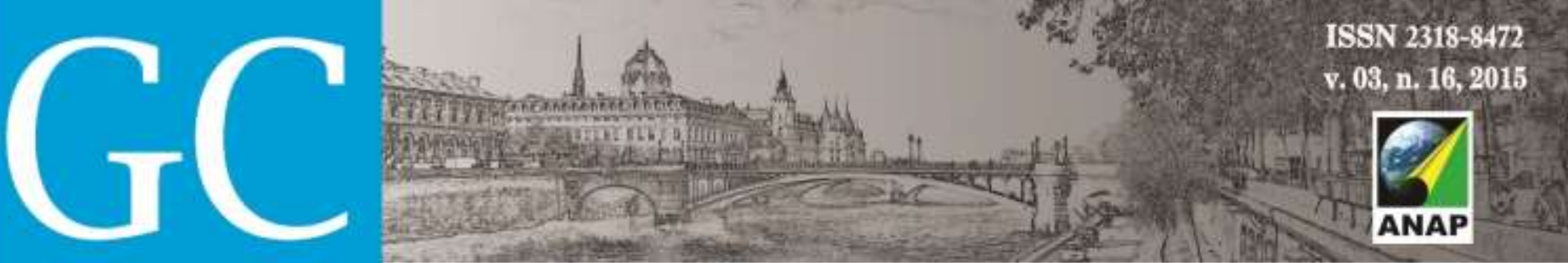

Revista Nacional de

Gerenciamento de Cidades

Marechal Hermes faz parte da Bacia Hidrográfica do Rio Acari (Figura 3), que é uma das maiores e mais populosas do município do Rio de Janeiro, possuindo mais de dez mil hectares.

Figura 3: Bacia Hidrográfica do Rio Acari

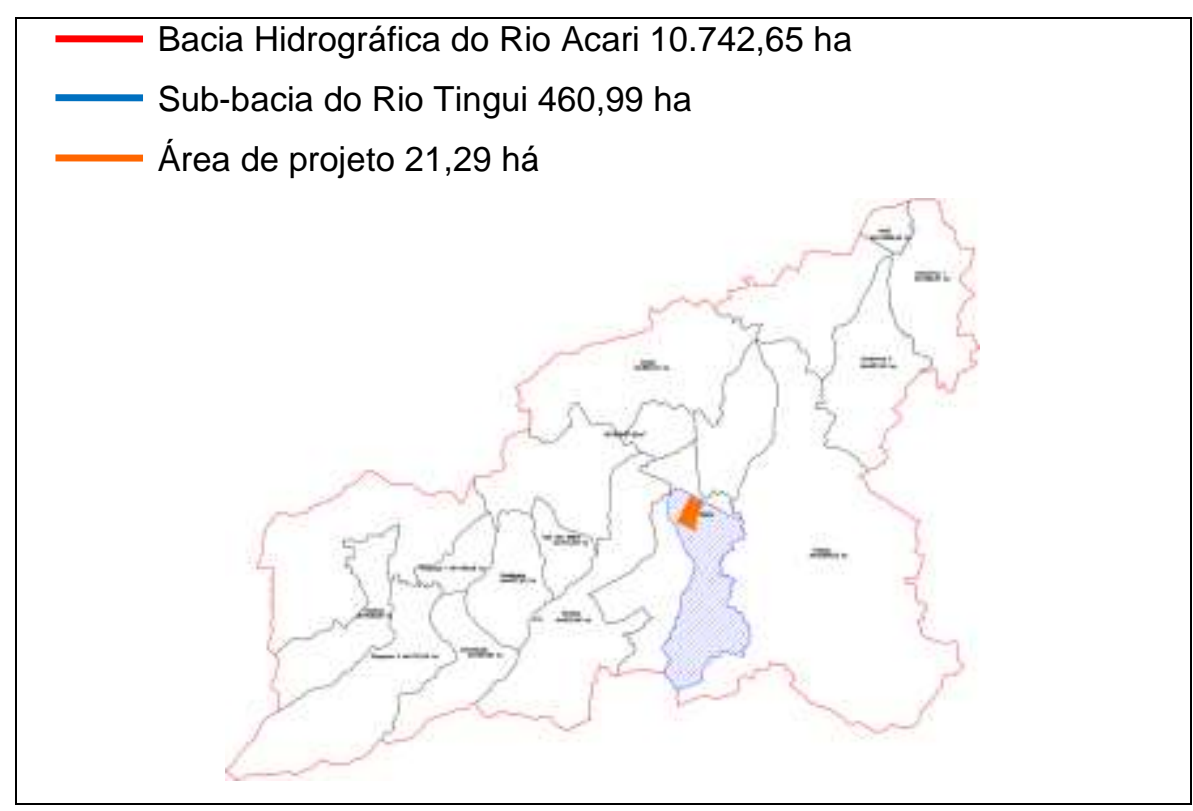

Fonte: Fundação COPPETEC/UFRJ (2007)

\subsection{PROPOSTAS}

Foram identificados os principais problemas na área da APAC de Marechal Hermes e traçadas estratégias projetuais em nível de desenho urbano que conciliassem a melhoria da drenagem com a da paisagem urbana do bairro, apresentando soluções para a requalificação dos espaços livres públicos, como praças, canteiros e calçadas. Os mesmos estão relacionados na tabela 1, a seguir. 
Tabela 1: Problemas relacionados ao desenho urbano e à drenagem urbana

\begin{tabular}{|c|c|c|}
\hline OBJETIVOS & ESTRATÉGIAS & PROJETO \\
\hline \multirow{2}{*}{$\begin{array}{c}\text { DRENAGEM URBANA } \\
\text { Fazer o escoamento das } \\
\text { águas devido às chuvas, } \\
\text { que desqualifica o bairro } \\
\text { atualmente }\end{array}$} & $\begin{array}{c}\text { CONTINUIDADE } \\
\text { Reforçar a importância do eixo } \\
\text { proporcionado pela Estação } \\
\text { Ferroviária, pelas praças Montese e } \\
\text { XV de Novembro e Teatro Armando } \\
\text { Gonzaga. }\end{array}$ & $\begin{array}{l}\text { Abrir novos trechos de vias e } \\
\text { fechar outros, usando como } \\
\text { elementos de continuidade } \\
\text { (canteiros) jardins drenantes. }\end{array}$ \\
\hline & $\begin{array}{c}\text { PERMEABILIDADE } \\
\text { Tornar o solo mais permeável, } \\
\text { públicos e privados, favorecendo a } \\
\text { infiltração nas calçadas, ruas e } \\
\text { áreas livres. }\end{array}$ & $\begin{array}{l}\text { Utilizar pavimentos permeáveis } \\
\text { que marquem a setorização e } \\
\text { trincheiras de infiltração nas } \\
\text { calçadas, pois permitem a } \\
\text { infiltração de parte de água da } \\
\text { chuva no solo, além de } \\
\text { reservatórios de lotes para cada } \\
\text { edificação } \\
\end{array}$ \\
\hline \multirow{3}{*}{$\begin{array}{c}\text { PAISAGEM } \\
\text { Recuperar o desenho } \\
\text { urbano dos espaços livres } \\
\text { (praças, canteiros e } \\
\text { calçadas) }\end{array}$} & $\begin{array}{c}\text { RECUPERAÇÃO } \\
\text { Recuperar a importância do } \\
\text { desenho histórico do bairro, } \\
\text { requalificando os bens edificados e } \\
\text { áreas livres. }\end{array}$ & $\begin{array}{l}\text { Reforçar o desenho urbano das } \\
\text { praças que servem como áreas } \\
\text { principais de acesso. }\end{array}$ \\
\hline & $\begin{array}{c}\text { ADAPTABILIDADE } \\
\text { Integrar a Praça Montese à Estação } \\
\text { Ferroviária e usá-la como } \\
\text { reservatório temporário para as } \\
\text { cheias da região (bacia de } \\
\text { detenção). }\end{array}$ & $\begin{array}{c}\text { Criar usos de permanência na } \\
\text { praça aliado ao de controle de } \\
\text { cheias no bairro. }\end{array}$ \\
\hline & $\begin{array}{l}\text { VITALIDADE/RESERVA DE ÁGUA } \\
\text { Rebaixar a praça XV de Novembro } \\
\text { para ser um elemento de } \\
\text { amortecimento das cheias, uma } \\
\text { bacia de detenção, com usos que } \\
\text { atendam as carências dos } \\
\text { equipamentos públicos e } \\
\text { residências que estão ao redor. }\end{array}$ & $\begin{array}{c}\text { Permitir ambiências } \\
\text { diferenciadas através de } \\
\text { patamares, favorecendo na } \\
\text { drenagem, com usos que } \\
\text { comportem essa demanda e a } \\
\text { das construções ao redor, } \\
\text { trazendo maior movimento ao } \\
\text { local. }\end{array}$ \\
\hline
\end{tabular}

\subsection{O REDESENHO URBANO E AS TÉCNICAS COMPENSATÓRIAS}

Como já mencionado, um dos principais problemas do bairro é a questão da falta de drenagem urbana, que resulta em cheias de tão notáveis proporções.

O trabalho realizado por Fundação COPPETEC (2007) consistiu na modelação hidráulica e hidrológica das cheias da região, o que permitiu avaliar o projeto de canalização existente e verificar o comportamento da bacia para a 
Revista Nacional de

Gerenciamento de Cidades

proposição de outras medidas para controle das cheias. A modelagem foi realizada com o MODCEL (MIGUEZ, 2001), modelo hidrodinâmico que utiliza o conceito de células de escoamento. A simulação para a situação atual da bacia do Rio Acari indica uma lâmina de alagamento de 2,09m na Praça Montese, valor este muito próximo daquele observado em janeiro de 2006, de 2,00m. Foi com base nas informações medidas em campo que o modelo foi calibrado. A partir daí, foram avaliados diferentes cenários, com proposições para a questão da drenagem urbana na região.

Dentre os cenários avaliados, aquele que apresentou melhor resposta, em termos de diminuição da lâmina d'água, foi o que previa serviços de dragagem conjugados com a implantação de reservatórios, a remodelação da Ponte Luiz Coutinho Cavalcanti (em Guadalupe) e a correção de capacidade de escoamento da rede, na região da Praça Montese. Nesse cenário, o nível de alagamento diminuiu para $0,50 \mathrm{~m}$, o que representa um abatimento de $75 \%$ da lâmina de alagamento da situação atual.

O trabalho aqui apresentado tomou como premissa a adoção das medidas propostas pela Fundação COPPETEC (2007), que obteve um resultado de 0,50m para a lâmina de alagamento e implementou novas medidas para minimizar, ainda mais, o problema de drenagem urbana no bairro, como utilização dos sistemas de trincheiras de infiltração, jardins drenantes, pavimentos permeáveis, bacias de detenção e reservatórios de lote.

O projeto urbano abarcou uma área de aproximadamente 21 ha, dentro do perímetro da APAC, requalificando, principalmente, o Centro do Bairro, isto é, o entorno imediato do eixo histórico da Av. Gal Osvaldo Cordeiro de Farias que liga a Estação Ferroviária de Marechal Hermes ao Teatro Armando Gonzaga (Figura 4). 


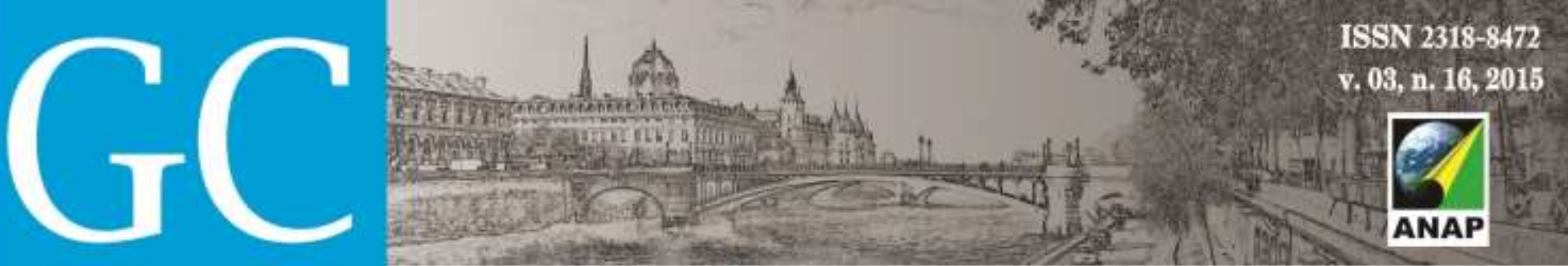

Revista Nacional de

Gerenciamento de Cidades

Figura 4: Divisão da área de projeto em quarteirões

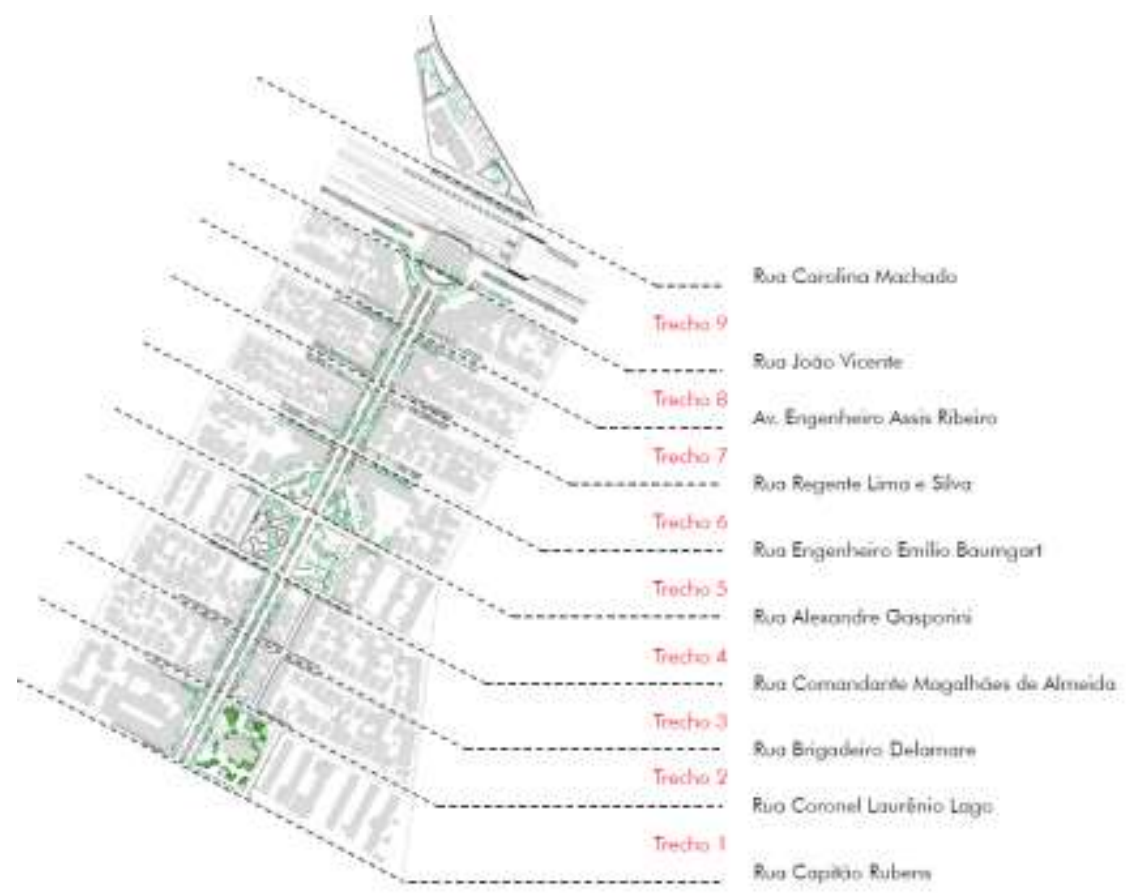

Fonte: Imagem elaborada pela autora ${ }^{1}$ sobre base cadastral.

\section{- Trincheiras de infiltração, Jardins drenantes e Pavimentos permeáveis:}

O sistema de jardins drenantes foi aplicado nos canteiros centrais das ruas, que, antes, tinham sua continuidade marcada por uma vegetação rala e por fradinhos. Os jardins reforçaram a importância do eixo existente, marcando-o e auxiliando no combate às cheias da região, além do embelezamento paisagístico proporcionado.

A técnica de trincheiras de infiltração foi aplicada nas bordas ao longo das calçadas, que, por serem cobertas com uma grelha, não conflitam com o uso das calçadas.

Os pavimentos permeáveis foram aplicados em todas as calçadas, nas ruas e nas praças. Para marcar a setorização proposta, foram usados: blocos intertravados de concreto coloridos marcando espaços de permanência, caminhos e separação de ambientes, asfalto poroso para as áreas de estacionamento, além de outros elementos, como bloco de concreto vazado com vegetação rasteira, 

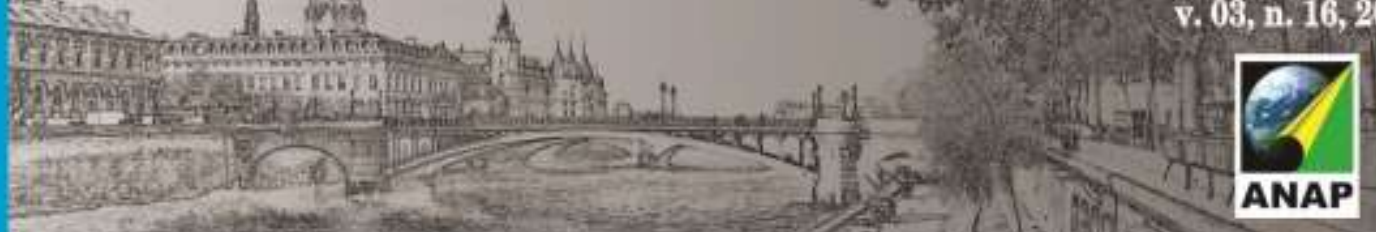

Revista Nacional de

Gerenciamento de Cidades

Figura 6: Detalhe das calçadas

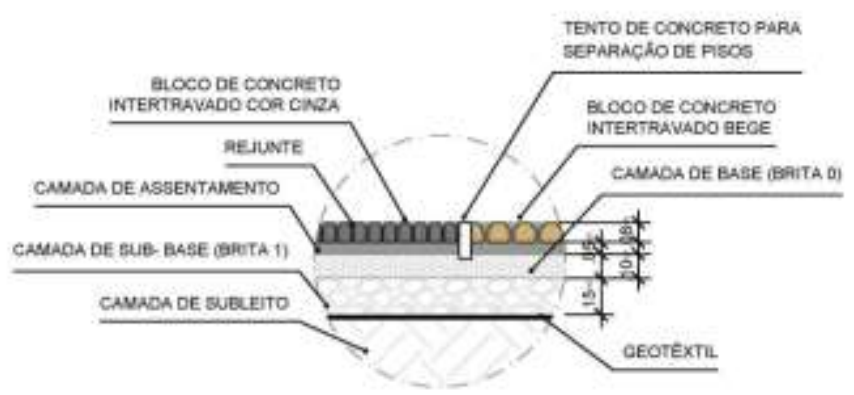

Fonte: Imagem elaborada pela autora ${ }^{1}$ com base na revista $\mathrm{RBRH}$, vol. 18 .

\section{- Bacias de detenção:}

Foi proposta uma bacia de detenção para a Praça Montese, em frente à Estação Ferroviária, atualmente configurado por um espaço árido. A praça foi rebaixada para conformar o sistema, ao mesmo tempo em que permitiu uma significativa área de permanência. O projeto resultante pode ser visto na Figura 7 .

Também foi adotada essa técnica na Praça XV de Novembro, que, atualmente, funciona como uma área única. Assim, foi proposta a divisão da mesma em quatro áreas que atendem melhor às demandas oferecidas ao redor, pelas escolas, de áreas livres de espera para os pais, próximas a elas, áreas de recreação infantil, para as moradias, de lazer para adultos e jovens, áreas esportivas e para atividades físicas e para os comércios, de espaços de permanência. A praça, agora dividida em quatro partes, foi rebaixada em patamares, com volumes mais baixos para amortecer cheias mais recorrentes e volumes maiores que serão inundados com menos frequência, utilizados para implantação de elementos de lazer e práticas de esportes. A figura 8 apresenta o desenho final dessa proposta. 


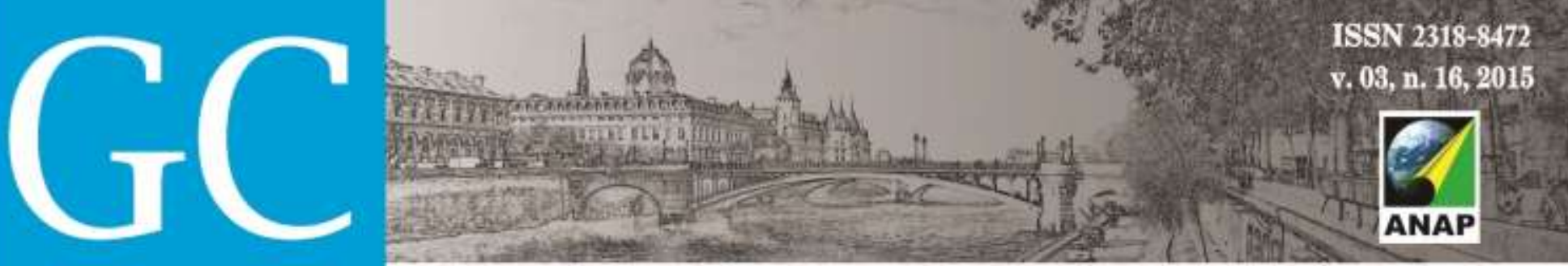

Revista Nacional de

Gerenciamento de Cidades

\section{- Reservatórios de lote:}

Foram propostos reservatórios de lote com volume de $1 \mathrm{~m}^{3}$ para as residências e comércios existentes na área de projeto, como um mecanismo de controle das cheias urbanas nessa região, visando o benefício não só do proprietário, mas, principalmente, da área como um todo. Na figura 9, pode-se ver o exemplo de aplicação desta técnica, de forma esquemática, em uma quadra da área de projeto.

Figura 9: Proposição de Reservatórios de lote $\left(1 \mathrm{~m}^{3}\right)$ em uma quadra no trecho 2

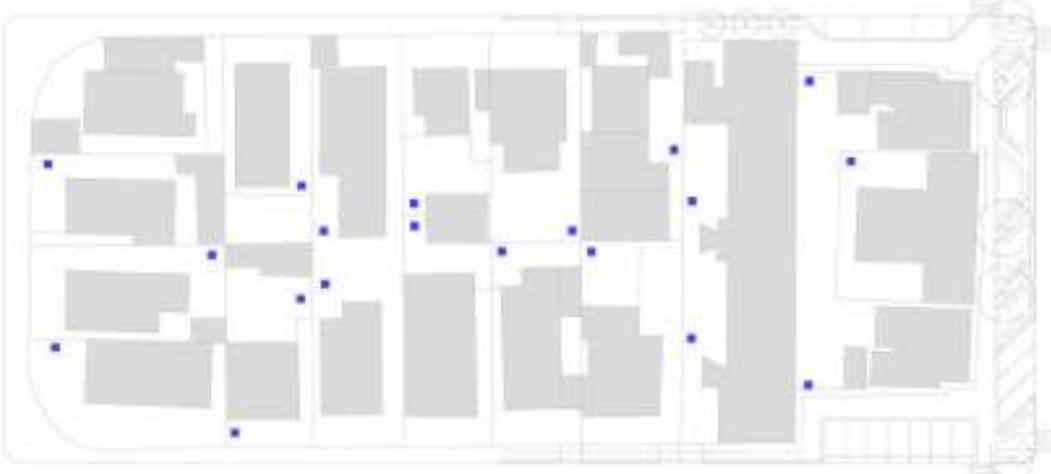

Fonte: Imagem elaborada pela autora ${ }^{1}$ sobre base cadastral.

A Figura 10 apresenta a imagem final do projeto proposto, tendo a Av. General Osvaldo Cordeiro de Farias como protagonista e a Estação Ferroviária nos fundos. Os canteiros centrais funcionam como jardins drenantes e as calçadas receberam elementos para circulação e permanência dos transeuntes, além da inserção de vegetação onde a mesma era faltante, requalificando o espaço urbano do bairro de Marechal Hermes. 


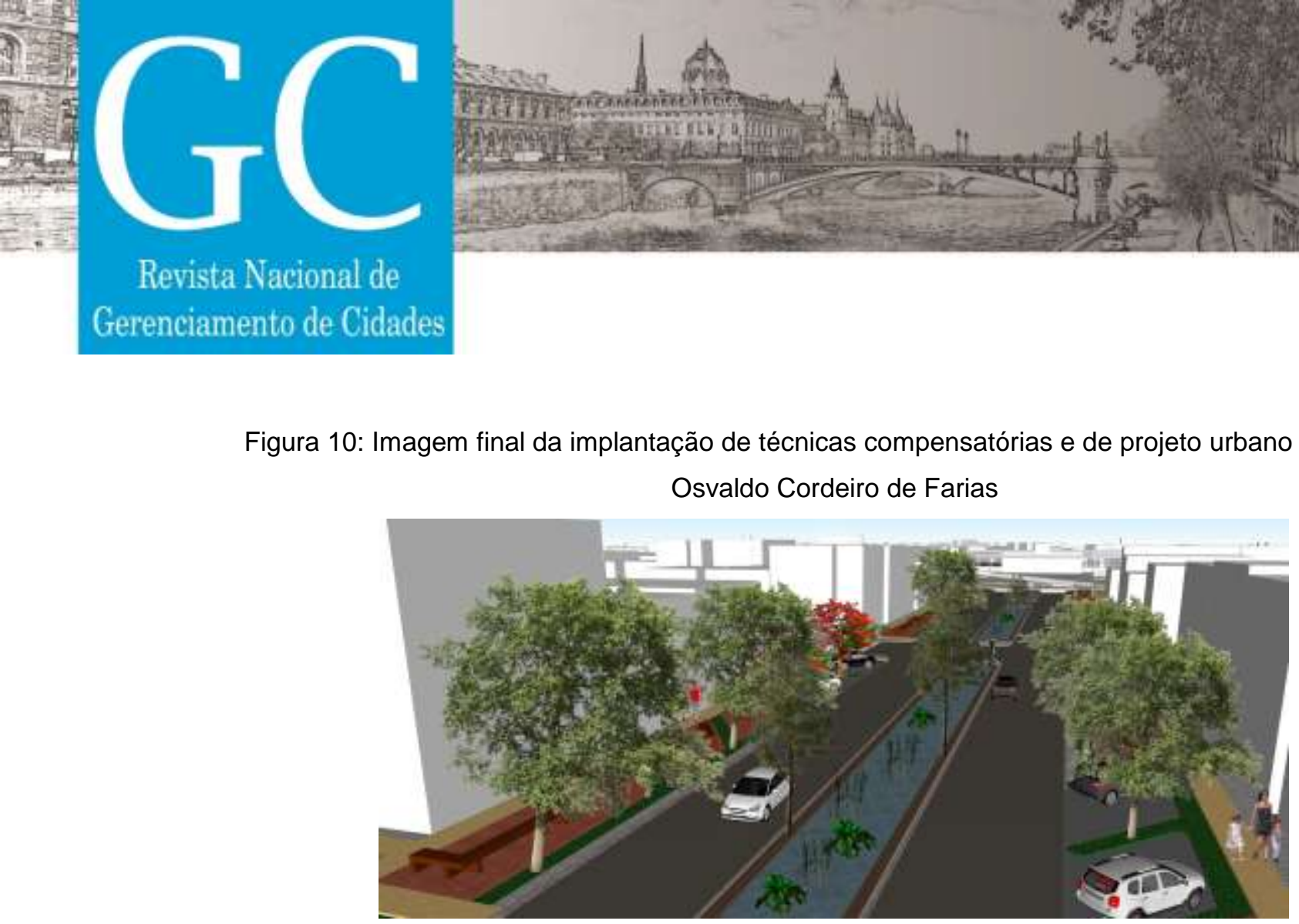

Fonte: Imagem elaborada pela autora ${ }^{1}$ com base em levantamentos tridimensionais e referências supracitadas.

\section{CONCLUSÃO / CONSIDERAÇÕES FINAIS}

A saturação dos sistemas tradicionais de drenagem urbana se torna evidente devido às cheias nas grandes cidades. Não existe solução padrão para resolver o problema de alagamentos em determinada região. A implantação de técnicas compensatórias auxilia no controle de cheias, possibilitando ações por toda a bacia e otimizando os recursos pelo poder público. O desenho urbano é de mais valia quando aliado a elementos de drenagem urbana, pois ganha um resultado melhor e atende às demandas do bairro, trazendo embelezamento, proporcionando usos devidos e auxiliando no problema primordial que são as cheias da região.

Neste projeto, que abordou o bairro de Marechal Hermes, no RJ, a área livre de maior alteração foi a Praça XV de Novembro, antes um grande espaço árido, propondo a divisão dessa com duas áreas livres retangulares, uma voltada à prática de esportes, especificamente o skate com algumas áreas livres de transição, outra com áreas livres divididas em patamares para permanência e no último patamar um anfiteatro. As duas outras partes propostas englobam as atividades de recreação e 


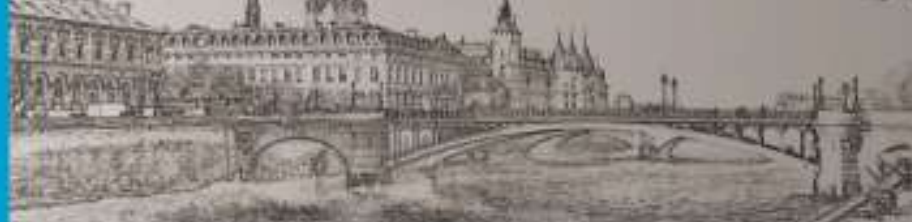

\section{Revista Nacional de}

Gerenciamento de Cidades

física, uma com jogos e atividade físicas (musculação) voltada para um público jovem e adulto e outra com recreação infantil e ginástica para a terceira idade.

Com o projeto proposto, o bairro de Marechal Hermes, atualmente quase esquecido pelo poder público, ganharia uma valorização maior, através da requalificação de suas áreas livres, seria mais utilizado pelos moradores e por quem trabalha na região, pois possuiria áreas que comportam as necessidades de uso, como áreas de permanência, áreas de lazer e de atividades físicas. As pessoas conseguiriam viver bem em épocas chuvosas, sem passar por situações de muitas vezes não conseguirem nem chegar ou sair de casa. O projeto não elimina os problemas com alagamento da região, pois esse é de escala maior, mas, melhora e muito a qualidade de vida da população do bairro, tornando-se possível o convívio em dias de chuva intensa.

Este trabalho contribui para um maior entendimento de como o desenho urbano pode ser aliado à drenagem urbana, através da inserção de técnicas compensatórias na conformação do mesmo, na mudança de áreas livres, adaptando-as a elementos de controle dos alagamentos.

Por ser um problema recorrente em muitos bairros no Brasil, a falta de planejamento urbano é um importante assunto para ser colocado em prática e estar cada vez mais presente na atualidade e no futuro em discussões técnicas e científicas.

\section{REFERÊNCIAS BIBLIOGRÁFICAS}

ALGODOAL, P. L. C. Drenagem Urbana em São Paulo. PROJ 4 - SIURB/PMSP, 2009.

AMEC, Earth and Environmental Center for Watershed Protection. Georgia Stormwater Manegement Manual, Volume 2: Technical Handbook. Atlanta, 2001.

BAPTISTA, M.; NASCIMENTO, N.; BARRAUD, S. Técnicas Compensatórias em Drenagem Urbana, ABRH, Porto Alegre, Brazil, 2005.

BRASIL. Lei Ordinária $n .011 .445$, de 5 de janeiro de 2007. Estabelece diretrizes nacionais para o saneamento básico; altera as Leis ns. 6.766, de 19 de dezembro de 1979, 8.036, de 11 de maio de 1990, 8.666, de 21 dejunho de 1993, 8.987, de 13 de fevereiro de 1995; revoga a Lei n. 6.528, de 11 
de maio de 1978; e dá outras providências. Brasília, 2007. Disponível em: http://www.planalto.gov.br/ccivil_03/_ato2007-2010/2007/lei/l11445.htm.

CASTRO, A. S.; GOLDENFUM, J. A.; SILVEIRA, A. L.; MARQUES, D. M. Avaliação da Evolução do Comportamento Quantitativo de Pavimentos Permeáveis no Controle do Escoamento Superficial. RBRH - Revista Brasileira de Recursos Hídricos Volume 18 n.1 - p. 263-273, Jan/Mar 2013.

DUARTE, R. X. M. Reservatórios de Lote para Drenagem Urbana. Trabalho Final de Graduação. Escola Politécnica, UFRJ, 2003.

Fundação COPPETEC/UFRJ. Estudos Integrados para Avaliação de Projeto de Intervenção na Calha do Rio Acari - RJ. R5 - Relatório Final Consolidado, 2007.

GOLDENFUM, J. A.; SOUZA, V. C. Trincheira de infiltração como elementos de controle de escoamento superficial: um estudo experimental. XIII Simpósio Brasileiro de Recursos Hídricos. Belo Horizonte, 11 p., 1999.

MAGALHÃES, L. P. C.; MIGUEZ, M. G.; MASCARENHAS, F. C. B.; MAGALHÃES, P.C.; MAGALHÃES, S.C.; DUARTE, R.X.M. Estudo da Aplicação de Um Reservatório de Lote com Múltiplos Usos. In: Anais do XV Simpósio Brasileiro de Recursos Hídricos. Curitiba/PR, 2003.

MIGUEZ, M.G., MASCARENHAS, F.C.B., MAGALHÃES, L.P.C. (2007). Multifunctional Landscapes For Urban Flood Control In Developing Countries. International Journal of Sustainable Development and Planning, Vol. 2, №2, pp. 153-166, ISSN 1743- 7601, 2007.

MIGUEZ, M. G. Modelo Matemático de Células de Escoamento para Bacias Urbanas. Tese de Doutorado, COPPE/UFRJ, Rio de Janeiro, 2001.

REZENDE, O. M.; MIGUEZ, M. G.; VERÓL, A. P. Manejo de Águas Urbanas e sua Relação com o Desenvolvimento Urbano em Bases Sustentáveis Integradas - Estudo de Caso dos Rios PilarCalombé, em Duque de Caxias/RJ. Revista Brasileira de Recursos Hídricos, v. 18, p. 149-163, 2013.

TECEDOR, N.; BAPTISTA, L. F. S.; FELIPE, M. C.; BARBASSA, A. P. Técnicas Compensatórias em Drenagem Urbana Aplicadas no Campus da UFScar. Anais. $5^{\circ}$ Simpósio de Tecnologia em Meio Ambiente e Recursos Hídricos - FATEC - Jahu, 2013.

VERÓL, A.P.; MIGUEZ, M. G. Bacias de Detenção e Retenção para o Controle de Cheias Urbanas - Aplicação na baixada de Jacarepaguá. 26을 Congresso Brasileiro de Engenharia Sanitária e Ambiental. ABES - Associação Brasileira de Engenharia Sanitária 8 e Ambiental, 2011. 